\title{
The Phenetic Distances of Jordanian Arabs from Other Human Populations Suggest a Major Genetic Drift from the Caucasoid Race
}

\author{
Firas Alsoleihat* and Ameen Khraisat \\ Department of Conservative Dentistry and Fixed Prosthodontics, Faculty of Dentistry, University of Jordan, \\ Amman, Jordan 11942
}

ABSTRACT The objectives were to determine the
expression frequency and sexual dimorphism of 16 non-
metric crown traits on the permanent dentitions of the
living Jordanians, and to assess the biological affinity
of this sample to 21 high-order groups based on these
traits. 360 Jordanian school children ( 176 males, 184
females; mean ages 15.5 , sd $=0.4$ years) were studied
in 2009 . The traits were classified using the Arizona
State University dental anthropology system, counted
with the individual count method, and dichotomized
according to Scott and Turner criteria for the purpose
of group comparisons. Z-value test was used to assess
sexual dimorphism in these traits. Smith's Mean

The study of dental morphological traits has been used extensively by dental morphologists, anthropologist and paleontologists for characterization and assessment of the biological relationships within and among ancestral, recent and living major subdivisions of humankind, and to a lesser extent for racial diagnosis in the field of forensic odontology (Dahlberg 1965b, 1986; Turner, 1987a; Scott and Turner, 1988, 1997; Irish, 1993; and others).

Dental morphological traits have been shown to be largely under the control of genes and minimally affected by environmental factors (Scott and Dahlberg, 1982; Corruccini et al., 1986; Sofaer et al., 1986), and have also been described to be genetically conservative, exhibiting minimal modification over many generations (Scott and Turner, 1988). However, the general evolutionary trend in the modern human dentition has been described to be toward morphologic simplification and tooth size reduction (Scott and Turner, 1988).

The utility of inter-population variation in the frequencies of dental non-metric (morphological) traits for measuring the biological distance between human populations has been well-demonstrated (Scott and Turner, 1997). Such biological distance values provide summary values that encapsulate the overall difference in the expression frequencies of these traits between two groups (Scott and Turner, 1997). Morphological or phenetic distances based on inter-population variation
Measure of Divergence was used to measure all pairwise distance values among the groups. Sexual dimorphism was found in only three traits (i.e., Carabelli's tubercle/ cusp, metaconule and hypoconulid absence). This study revealed that the dental pattern of living Jordanians is sufficiently distinct from the Caucasoid pattern and all other known dental patterns to warrant a unique dental pattern for this population. Moreover, the relatively large distance values between the living Jordanians and all other world groups considered including the Western Eurasian groups suggest a major genetic drift for this population from the Caucasoid race. Dental Anthroology 2011;24:23-30.

in the frequencies of dental morphological traits have been shown to be powerful in assessing biological affinity between population groups, since these traits have a strong heritable component (Scott and Turner, 1997). In general, small inter-group distances indicate that these groups are biologically similar and have a recent common ancestor, while large values are associated with biological dissimilarity and remote common ancestry (Scott and Turner, 1997). However, significant admixture (gene flow) between groups leads to convergence which can change the original biological distance between these groups (Scott and Turner, 1997).

The dental pattern of living Jordanian Arabs has not been comprehensively studied before, and the biological affinity of this population for other geographic races has not been assessed.

Sexual dimorphism for dental morphological traits has been investigated by many workers, and the reported results are not always consistent and appear to show geographic variation among various world groups. An exception of this is the distal accessory ridge

*Correspondence to: Firas Alsoleihat, Department of Conservative Dentistry, Faculty of Dentistry, University of Jordan, Amman, 11942 Jordan

Tel: (+962) 777946631

E-mail: firas.alsoleihat@ju.edu.jo 
of the upper and lower canines which exhibits consistent dimorphism between males and females across diverse groups (Scott, 1977a; Kaul and Prakash, 1981; Kieser and Preston, 1981; Scott et al., 1983). Apart from this variable, some researchers have found statistically significant male-female differences in the expression of some dental morphological traits such as Carabelli's trait (Goose and Lee, 1971; Kaul and Prakash, 1981; Kieser and Preston, 1981; Townsend and Brown, 1981b, Scott et al., 1983; Mizoguchi, 1985) and upper central incisor shoveling (Rothhammer et al., 1968; Harris, 1980) while others found no sex difference for Carabelli's trait (Garn et al., 1966d; Turner, 1969; Scott, 1980; Townsend et al., 1992) and the shoveling trait (Aas and Risnes, 1979a; Mizoguchi, 1985).

The aims of the present study were, first, to investigate the frequencies and sexual dimorphism of 16 dental morphological traits, that are observable on dental stone casts on the permanent dentition of the living Jordanian Arabs, and, second, to assess the biological affinity of the living Jordanians in a global context by measuring all of the pairwise biological distances among this group and 21 other high-order regional groups from the five major subdivisions of humankind based on the variation of frequencies of the dental traits.

\section{MATERIALS AND METHODS}

\section{Sample and Inclusion Criteria}

A random stratified sample was obtained in 2009 by selecting 370 tenth grade school children (180 males and 190 females), from 12 schools representing the six regional directories of the capital city of Jordan, Amman. Informed consents were obtained from the parents of all children who chose to participate in the study before the children were subjected to dental examination or impression taking. The average age of the selected subjects was 15 years $(\mathrm{sd}=0.4)$. They were selected according to the following criteria: all subjects were apparently healthy with no history of serious childhood illnesses, have erupted second molars, showing well aligned arches with no supernumerary teeth and no history of orthodontic treatment, with normal appearing teeth, no large restorations or fixed replacements, and minimal marks of caries or attrition.

Alginate impressions for the upper and lower dental arches were taken (Lascod S.p.A, Firenze, Italy). Impressions were poured with type IV dental stone (Elite stone, Zhermack S.p.A, Badia Polesine, Italy) within one hour of impression taking. Casts of ten subjects were excluded due to technical errors such as air bubbles. The remaining casts were of 176 male and 184 female students.

\section{Observation Method}

Sixteen morphological tooth crown traits were observed and classified according to the standard plaques of the Arizona State University dental anthropology system (Turner et al., 1991). All observations were carried out by under good lighting and using 10X hand lenses. The individual count method was used here to estimate the frequency of expression of the dental morphological traits. According to this method, the antimere exhibiting the highest grade of trait expression is used for statistical analysis (Scott and Turner, 1997). This method was chosen because it assigns each individual a phenotypic value that is thought to best represent the individual genotype and it does not artificially inflate the sample size like the total side (tooth) count method (Scott and Turner, 1997). Such increase in sample size would affect most statistical analyses (Scott and Turner, 1997).

\section{Intraobserver Error}

All observations for these morphological traits were carried out by one well-trained observer. Intra-observer reliability for scoring these traits was assessed according to Nichol and Turner criteria (1986). 30 dental casts out of the present sample were selected, to be scored by the single observer, and rescored by the same observer three months later. Care was taken to reproduce the percentages of males and females in this sample as in the original sample of 360 casts. Percentages of disagreements that are of two grades or more between the two scoring sessions (>1 Grade Variant Scoring \%) were calculated for the traits considered here and found to be less than the critical value of $10 \%$ as set by Nichol and Turner (1986) who justified that traits generating greater than $10 \%$ disagreement of two or more grades between two scoring sessions are difficult to reliably score since they reflect either recording error, inaccurate observational method, or difficulties with standard plaque itself rather than the natural difficulty in the ability to consistently classify individuals exhibiting intermediate trait expression between two grade standards on a ranked scale. In addition, the Net Mean Grade Difference (NMGD) between the two scoring sessions was calculated for these traits using the formula $\mathrm{NMGD}=\left(\Sigma\left(\mathrm{X}_{2}-\mathrm{X}_{1}\right) / \mathrm{n}\right) \times 100$

where $X_{1}=$ the grade number assigned to a cast for a trait in the first scoring session; $X_{2}=$ the grade number assigned to the same cast for the same trait in the second scoring session; and $\mathrm{n}$ is the number of casts that were observed in both of the scoring sessions.

The calculated NMGD value for each trait considered here was found below the critical level of NMGD for that trait, which is $>5 \%$ multiplied by the number of the highest grade on the grading standard for that trait.

Furthermore, the differences between the mean scores of the two scoring sessions for these traits were 
estimated using the paired sample t-test and the $t$-values were found to be below the critical 0.05 probability level adjusted by Bonferroni's method (Miller, 1966; Nichol and Turner, 1986). It should be noted that dental morphological traits are ordinal scale variables and the t-test is an interval scale statistics, however, since the graded scales for scoring these traits were designed so that the variation in expression of these traits is divided into equal intervals from the least to greatest expression (Scott, 1973), it is justifiable, according to Nichol and Turner (1986), to use the t-test with non-metric dental traits based on the assumption that the classification grades are equally spaced on the ranked scales for these traits.

Given the foregoing values (the values of the $>1$ Grade Variant Scoring \%, of NMGD and the t-values), it can be concluded that the scoring of these traits is reliable and that the intra-observer error in scoring these traits can be considered random and statistically insignificant.

\section{Statistical Analysis and Visual Depiction}

Social Science Statistical Package Software (SPSS, Version 17.0, Inc., Chicago, IL) was used to analyze the data. Frequencies were calculated for crown traits and dichotomized according to Scott and Turner criteria (1997) for the purpose of group comparisons to quantify their relative prevalence among the living Jordanian sample. Z-value test was used to test any significant difference in trait expression between males and females using software available on the following website:

(http:/ / www.dimensionresearch.com/resources/ calculators/ztest.html).

For the purpose of affinity assessment, the biological distances among the living Jordanians and 21 highorder regional groups from the five major subdivision of humankind were measured using CAB Smith's Mean Measure of Divergence (MMD) based on the variation in the frequencies of expression of 16 non-metric tooth crown traits among these groups (ConstandseWestermann, 1972; Harris and Sjøvold, 2004). This analysis was based on our own data for the frequencies of these traits among the living Jordanians and on the data available in Scott and Turner (1997) regarding the frequencies of the same traits among the other 21 regional groups and the corresponding sample sizes. Anscombe's angular transformation formula was adopted here to transform frequencies into angles for calculating the Smith's MMD in order to stabilize sampling variances of binomial variables, since this formula is the recommended angular transformation method by Rao (1952) for moderately large samples (Harris and Sjøvold, 2004). It should be noted that the MMD value between any two groups being compared was measured as recommended by Harris and Sjøvold (2004) by calculating the differences between the two groups in angularly transformed frequencies of each trait, then this difference is squared so that positive and negative differences do not cancel one another, then the correction term $\left(\left(1 / \mathrm{n}_{1 \mathrm{k}}+0.5\right)+\left(1 / \mathrm{n}_{2 \mathrm{k}}+0.5\right)\right)$ is subtracted from this squared difference for each trait (hence the subscript k) in order to adjust for the overestimation of divergence between corresponding groups generated by the squared difference between two angular values, then the resultant values for all traits used in the equation are summed and then the sum is divided by the number of these traits (Harris and Sjøvold, 2004). The resultant matrix of distance values corresponding to all pairwise comparisons among the 22 groups was used to derive two coordinates (two-dimensional ordination) for each group through multidimensional scaling using SPSS statistics 17.0 in order to reduce the complexities of the distance matrix to two dimensions and to provide graphical representation for the biological distances among the 22 groups considered.

\section{RESULTS}

\section{Crown Trait Frequencies}

Table 1 summarizes the frequencies of 16 nonmetric dental crown traits, on the permanent dentition in both sexes among the living Jordanian sample. By comparing the frequencies of the 16 traits among the living Jordanians with the world ranges of these traits, it is apparent that the dental pattern of the living Jordanians shows distinctly high frequencies of double shoveling on UI1, Carabelli's trait and cusp 5 (metaconule) on UM1; high frequencies of interruption grooves on UI2, hypocone absence (3-cusped form) on UM2 and Bushmen canine trait on UC; intermediate frequencies of shoveling on UI1, hypoconulid absence on LM2, deflecting wrinkle, cusp 6 and 7 on LM1; low frequencies of bilateral winging of UI1s, $Y$ pattern on LM2, hypoconulid absence and distal trigonid crest on LM1, and absence of premolar odontomes (Table 1).

\section{Sexual Dimorphism}

Statistically significant male-female differences were found in only three of the 16 dental morphological traits. These include the Carabelli's trait (tubercle and cusp forms only) and cusp 5 (distal accessory tubercle, metaconule) on UM1, and hypoconulid absence (4-cusped form) on LM1. In the first two traits the difference is in favor of males while in the third one it is in favor of females (Table 1).

\section{Phenetic Distances Among 22 Regional Groupings}

Table 2 shows a matrix of all the pairwise biological distances among 22 high-order regional groupings including the living Jordanian Arabs based on intergroup variation in the frequencies of the 16 crown traits. 
TABLE 1. Frequencies of 16 dental morphological traits among the living Jordanians (individual count, affected individuals/ total number of subjects in parentheses)

\begin{tabular}{|c|c|c|c|c|c|c|c|}
\hline $\begin{array}{l}\text { Trait } \\
\text { name }\end{array}$ & Tooth & Breakpoint & $\begin{array}{l}\text { World } \\
\text { range }\end{array}$ & $\begin{array}{l}\text { Percent } \\
\text { Males }\end{array}$ & $\begin{array}{l}\text { Percent } \\
\text { Females }\end{array}$ & Z-value & $\begin{array}{c}\text { Percent } \\
\text { (sexes pooled) }\end{array}$ \\
\hline Winging & UI1 & $\begin{array}{c}\text { Grade } 1 \\
\text { (bilateral winging) }\end{array}$ & $4.2-50.0 \%$ & $\begin{array}{c}8.0 \% \\
(14 / 176)\end{array}$ & $\begin{array}{c}8.7 \% \\
(16 / 184)\end{array}$ & 0.067 & $\begin{array}{c}8.3 \% \\
(30 / 360\end{array}$ \\
\hline Shoveling & UI1 & $\begin{array}{c}\text { Grades 3-6 } \\
\text { (Hrdlicka's } \\
\text { semi- and full-shovel) }\end{array}$ & $0.0-91.9 \%$ & $\begin{array}{c}55.7 \% \\
(98 / 176)\end{array}$ & $\begin{array}{c}56.0 \% \\
(103 / 184)\end{array}$ & -0.049 & $\begin{array}{c}55.8 \% \\
(201 / 360)\end{array}$ \\
\hline $\begin{array}{l}\text { Double } \\
\text { Shoveling }\end{array}$ & UI1 & Grades 2-6 & $0.0-70.5 \%$ & $\begin{array}{c}98.3 \% \\
(173 / 176)\end{array}$ & $\begin{array}{c}94.6 \% \\
(174 / 184)\end{array}$ & 1.614 & $\begin{array}{c}96.4 \% \\
(347 / 360)\end{array}$ \\
\hline $\begin{array}{l}\text { Interruption } \\
\text { Grooves }\end{array}$ & UI2 & $\begin{array}{c}\text { Grade } 1 \\
\text { (total frequency) }\end{array}$ & $10.4-65.0 \%$ & $\begin{array}{c}63.6 \% \\
(112 / 176)\end{array}$ & $\begin{array}{c}61.4 \% \\
(113 / 184)\end{array}$ & 0.328 & $\begin{array}{c}62.5 \% \\
(225 / 360)\end{array}$ \\
\hline $\begin{array}{l}\text { Bushmen } \\
\text { Canine }\end{array}$ & UC & $\begin{array}{c}\text { Grades } 1-3 \\
\text { (total frequency) }\end{array}$ & $0.0-35.1 \%$ & $\begin{array}{c}30.7 \% \\
(54 / 176)\end{array}$ & $\begin{array}{c}27.2 \% \\
(50 / 184)\end{array}$ & 0.618 & $\begin{array}{c}28.9 \% \\
(104 / 360)\end{array}$ \\
\hline Odontomes U & $\begin{array}{l}\text { UPMs and } \\
\text { LPMs }\end{array}$ & $\begin{array}{c}\text { Grade } 1 \\
\text { (total frequency) }\end{array}$ & $0.0-6.5 \%$ & $\begin{array}{c}0.0 \% \\
(0 / 176)\end{array}$ & $\begin{array}{c}0.0 \% \\
(0 / 184)\end{array}$ & - & $\begin{array}{c}0.0 \% \\
(0 / 360)\end{array}$ \\
\hline 3-Cusped & UM2 & $\begin{array}{c}\text { Grades 0-1 } \\
\text { (equivalent to } 3 \\
\text { on Dahlberg scale) }\end{array}$ & $3.3-30.6 \%$ & $\begin{array}{c}26.7 \% \\
(47 / 176)\end{array}$ & $\begin{array}{c}19.0 \% \\
(35 / 184)\end{array}$ & 1.611 & $\begin{array}{c}22.8 \% \\
(82 / 360)\end{array}$ \\
\hline $\begin{array}{l}\text { Carabelli's } \\
\text { Trait }\end{array}$ & UM1 & $\begin{array}{c}\text { Grades 5-7 } \\
\text { (tubercle and } \\
\text { cusp forms only) }\end{array}$ & $1.9-36.0 \%$ & $\begin{array}{c}51.7 \% \\
(64 / 184)\end{array}$ & $\begin{array}{c}34.8 \% \\
(91 / 176)\end{array}$ & $3.134 a$ & $\begin{array}{c}43.1 \% \\
(155 / 360)\end{array}$ \\
\hline Cusp 5 & UM1 & $\begin{array}{c}\text { Grades 1-5 } \\
\text { (total frequency) }\end{array}$ & $10.4-62.5 \%$ & $\begin{array}{c}69.3 \% \\
(122 / 176)\end{array}$ & $\begin{array}{c}57.6 \% \\
(106 / 184)\end{array}$ & $2.195 a$ & $\begin{array}{c}63.3 \% \\
(228 / 360)\end{array}$ \\
\hline 4-Cusped & LM1 & $\begin{array}{c}\text { Grade 0 } \\
\text { (4-cusped LM1) }\end{array}$ & $0.0-10.0 \%$ & $\begin{array}{c}0.0 \% \\
(0 / 176)\end{array}$ & $\begin{array}{c}3.8 \% \\
(7 / 184)\end{array}$ & $2.228 \mathrm{a}$ & $\begin{array}{c}1.9 \% \\
(7 / 360)\end{array}$ \\
\hline 4-Cusped & LM2 & $\begin{array}{l}\text { Grade } 0 \\
\text { (4-cusped) }\end{array}$ & $4.4-84.4 \%$ & $\begin{array}{c}73.3 \% \\
(129 / 176)\end{array}$ & $\begin{array}{c}81.0 \% \\
(149 / 184)\end{array}$ & 1.611 & $\begin{array}{c}77.2 \\
(278 / 360)\end{array}$ \\
\hline Y Pattern & LM2 & Y pattern & $7.6-71.9 \%$ & $\begin{array}{c}21.0 \% \\
(37 / 176)\end{array}$ & $\begin{array}{c}19.0 \% \\
(35 / 184)\end{array}$ & 0.342 & $\begin{array}{c}20.0 \% \\
(72 / 360)\end{array}$ \\
\hline Cusp 6 & LM1 & $\begin{array}{c}\text { Grades } 1-5 \\
\text { (total frequency) }\end{array}$ & $4.7-61.7 \%$ & $\begin{array}{c}17.6 \% \\
(31 / 176)\end{array}$ & $\begin{array}{c}13.6 \% \\
(25 / 184)\end{array}$ & 0.907 & $\begin{array}{c}15.6 \% \\
(56 / 360)\end{array}$ \\
\hline Cusp 7 & LM1 & $\begin{array}{c}\text { Grades 1-4 } \\
\text { (total frequency } \\
\text { excluding grade 1A) }\end{array}$ & $3.1-43.7 \%$ & $\begin{array}{c}21.0 \% \\
(37 / 176)\end{array}$ & $\begin{array}{c}15.2 \% \\
(28 / 184)\end{array}$ & 1.293 & $\begin{array}{c}18.1 \% \\
(65 / 360)\end{array}$ \\
\hline $\begin{array}{l}\text { Deflecting } \\
\text { Wrinkle }\end{array}$ & LM1 & Grade 3 & $4.9-39.5 \%$ & $\begin{array}{c}23.3 \% \\
(41 / 176)\end{array}$ & $\begin{array}{c}19.0 \% \\
(35 / 184)\end{array}$ & 0.866 & $\begin{array}{c}21.1 \% \\
(76 / 360)\end{array}$ \\
\hline $\begin{array}{l}\text { Distal } \\
\text { Trigonid Crest }\end{array}$ & $\begin{array}{l}\text { LM1 } \\
\text { st }\end{array}$ & $\begin{array}{c}\text { Grade } 1 \\
\text { (presence) }\end{array}$ & $0.0-18.7 \%$ & $\begin{array}{c}5.7 \% \\
(10 / 176)\end{array}$ & $\begin{array}{c}9.8 \% \\
(18 / 184)\end{array}$ & 1.255 & $\begin{array}{c}7.8 \% \\
(28 / 360)\end{array}$ \\
\hline
\end{tabular}

athe difference is statistically significant at the 0.05 probability level (2-tailed).

UI1: upper central incisor; UI2: upper lateral incisor; UC: upper canine; UPMs: upper first and second premolars; LPMs: lower first and second premolars; UM1: upper first molar; UM2: upper second molar; LM1: lower first molar; LM2: lower second molar 


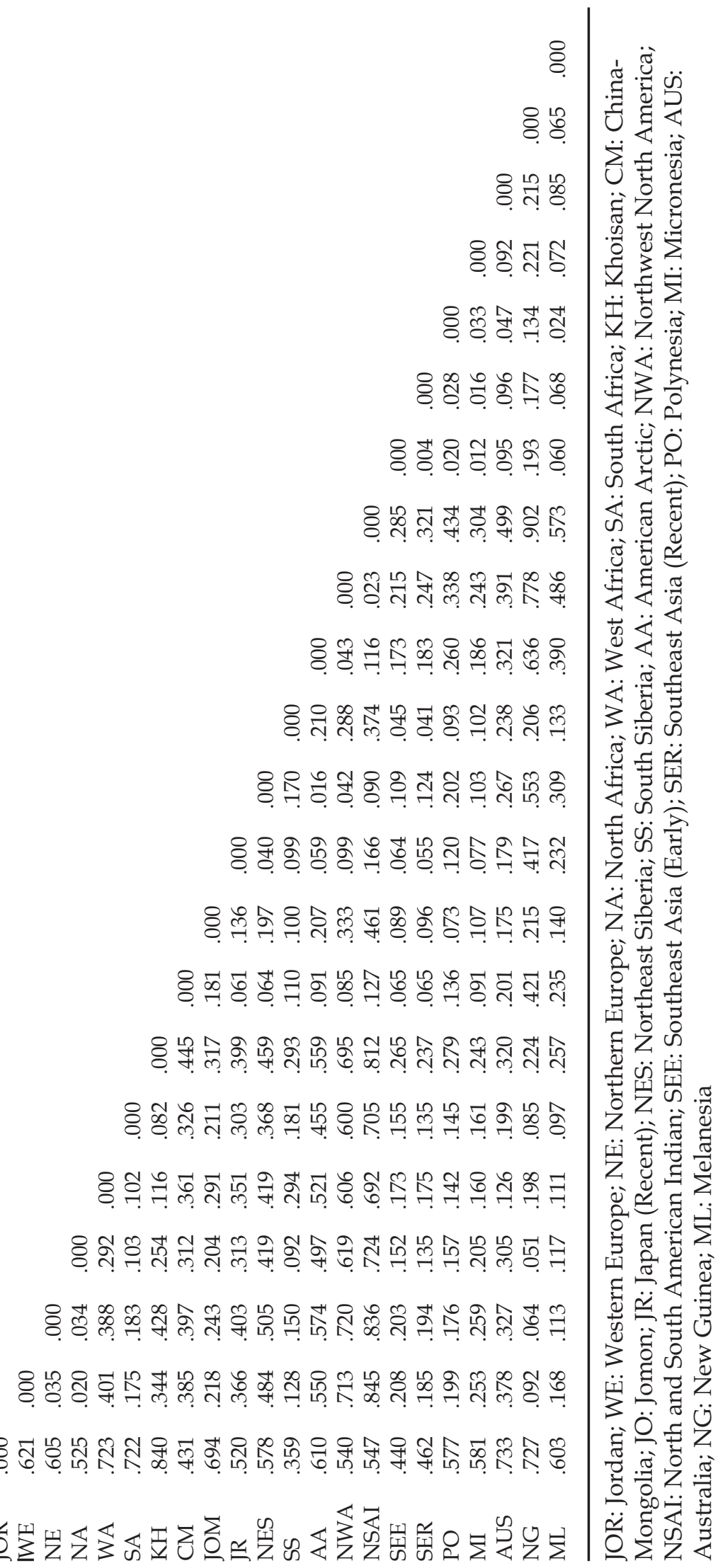




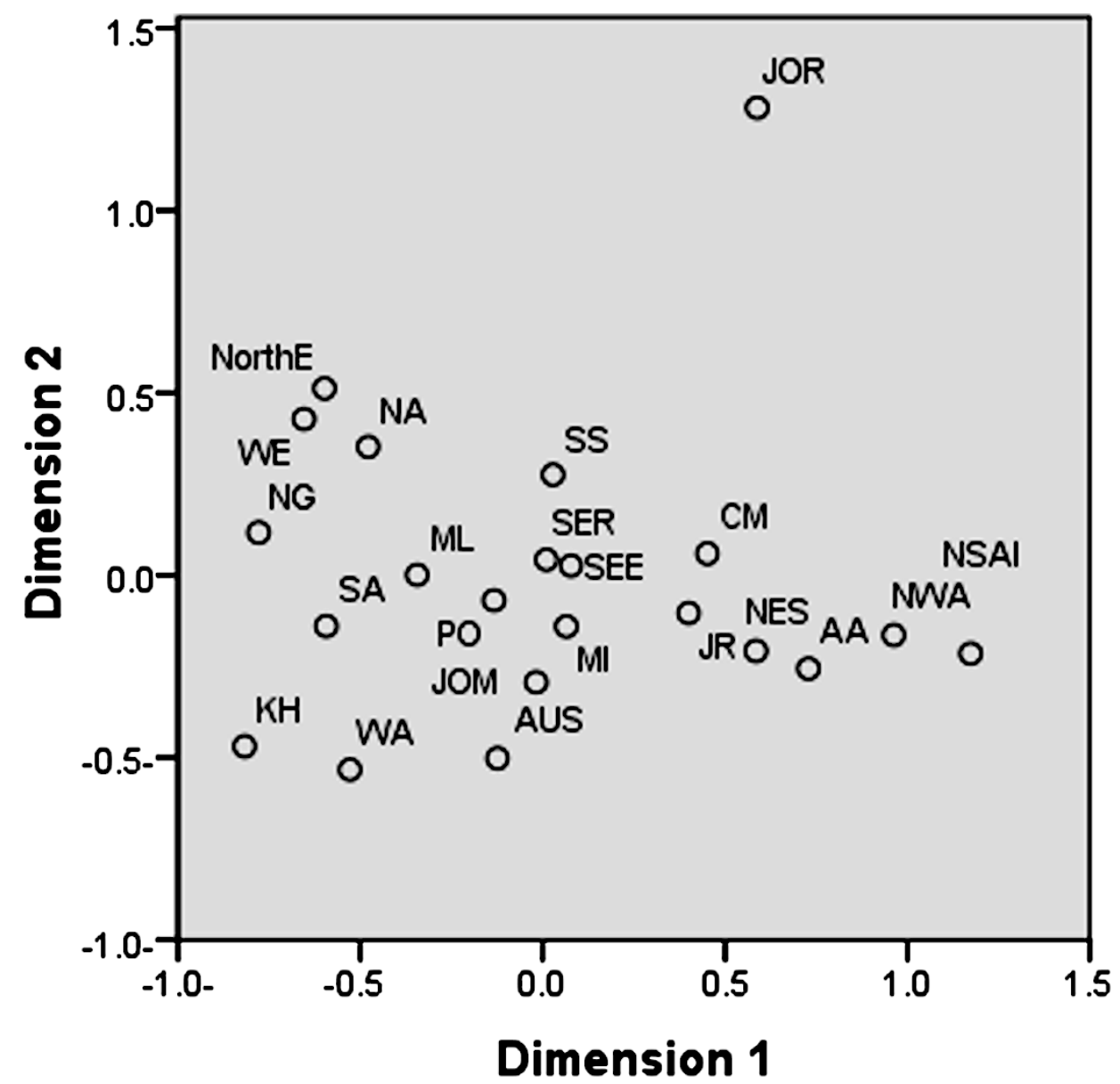

Fig. 1. Two-dimensional ordination based on multidimensional scaling of distance matrix for 16 non-metric crown traits in 22 regional groupings including the living Jordanian Arabs.

Abbreviations are: JOR: Jordan; WE: Western Europe; NorthE: Northern Europe; NA: North Africa; WA: West Africa; SA: South Africa; KH: Khoisan; CM: China-Mongolia; JO: Jomon; JR: Japan (Recent); NES: Northeast Siberia; SS: South Siberia; AA: American Arctic; NWA: Northwest North America; NSAI: North and South American Indian; SEE: Southeast Asia (Early); SER: Southeast Asia (Recent); PO: Polynesia; MI: Micronesia; AUS: Australia; NG: New Guinea; ML: Melanesia

None of the 21 regional groups is found apparently biologically close to the living Jordanians; however, the smaller distance values to the living Jordanians are those corresponding to South Siberia, China-Mongolia and Southeast Asia (Recent and Prehistoric) and, surprisingly, not to Western Eurasian groups (Western Europe, Northern Europe and North Africa).

Figure 1 provides a visual representation of the distance matrix shown in Table 2 by reducing these values to two dimensions through multidimensional scaling. It shows that the living Jordanian Arabs appear as an outlier and do not cluster with any of the 21 regional groups. However, relatively speaking, the Jordanian groups appear closer to South Siberia, ChinaMongolia and Southeast Asia than to Western Eurasian groups.

\section{DISCUSSION}

\section{Dental Morphological Pattern of Living Jordanians}

The results of this study revealed that the living Jordanian Arabs have a unique dental morphological pattern exhibiting outstandingly high frequencies of UI1 double shoveling and UM1 Carabelli's tubercle/cusp forms that set this population apart from other world groups. Moreover, this population falls at the high end of the global scale for five crown traits (i.e., UM1 cusp 5, UI2 interruption grooves, 3-cusped UM2, 4-cusped LM2, and UC Bushmen canine trait). In addition, UI1 shoveling assumes high intermediate position on the world range for this population group. Additionally, this group shows intermediate frequencies for deflecting 
wrinkle, cusp 6 and 7 on LM1. The remainder of crown traits described is at the low end of world variation (i.e., UI1s bilateral winging, LM2 Y pattern, 4-cusped LM1, LM1 distal trigonid crest; and premolar odontomes). This pattern is apparently distinct from the Western Eurasian, or Caucasoid, dental pattern, which is characterized by (A) high frequencies of 4-cusped lower first and second molars, Carabelli's tubercle/cusp, and 3-cusped upper second molars, but the latter two traits are not distinctly high in this regional subdivision and are nearly equaled by groups in other regions, (B) intermediate frequencies of UI2 interruption grooves and LM2 Y pattern; and (C) low frequencies of the remainder of the crown traits described (i.e., winging, shoveling, double shoveling, Bushmen canine, metaconule, cusp 6, cusp 7, deflecting wrinkle, distal trigonid crest, and premolar odontomes) (Scott and Turner, 1997). To summarize, the dental morphological pattern of living Jordanian Arabs is characterized by trait elaboration in contrast to that of Western Eurasians, which is felt by many researchers to be distinguished more by trait rarity or absence than trait elaboration (Mayhall et al., 1982; Scott and Turner, 1997).

\section{Sexual Dimorphism}

Sexual dimorphism among the living Jordanians was found statistically significant in only three out of the 16 crown traits described (i.e., UM1 cusp 5, UM1 Carabelli's tubercle/cusp forms and 4-cusped LM1), where the first two variables are more frequent in males and the latter shows a higher occurrence in females, indicating a stronger trend toward crown morphological reduction or simplification in females among the living Jordanian Arabs, and this reduction trend involves not only accessory tubercles and cusps but also major cusps of molar teeth. As mentioned before, it seems that there are differences among populations regarding the sexual dimorphism in the expression of Carabelli's trait; many workers found statistically significant male-female differences in favor of males (Goose and Lee, 1971; Kaul and Prakash, 1981; Kieser and Preston, 1981; Townsend and Brown, 1981b, Scott et al., 1983; Mizoguchi, 1985), but others find no sex difference for this trait (Garn et al., 1966d; Turner, 1969; Scott, 1980; Townsend et al., 1992). Consistent with our results regarding the sexual dimorphism in UM1 Carabelli's tubercle/cusp and 4-cusped LM1 is the report that Carabelli's trait in upper molars and hypoconulid expression (5-cusped form) in lower molars are less frequent in individuals with Turner syndrome $(\mathrm{XO}$ or $45, \mathrm{X})$ than their relatives (Kirveskari and Alvesalo, 1982). These findings suggest a role for the $\mathrm{X}$ chromosome in favoring crown morphological simplification versus a balancing effect of the $\mathrm{Y}$ chromosome in retaining crown morphological complexity.

\section{Biological Affinity of Living Jordanians}

The biological distance values between the living Jordanians and 21 high-order groups from the five major subdivisions of humankind based on the 16 crown traits described, as well as the visual depiction of the distance matrix described based on multidimensional scaling, show that the living Jordanians are phenetically distant from the Western Eurasian groups and all other world groups. These suggest that the living Jordanian population has undergone a major genetic drift that set the dental phenotype of this population apart from that of the Western Eurasian groups included in the analysis (i.e., Western Europeans, Northern Europeans and North Africans). Although less in magnitude, similar dental morphological differentiation among groups having recent common ancestral relationships has been well documented in the Middle Eastern Jews (Sofaer et al., 1986), the Southwest American Indians (Scott and Dahlberg, 1982; Scott et al., 1983), the Yanomama Indians of Venezuela (Brewer-Carias et al., 1976), and Melanesians (Harris, 1977). Such genetic drifts leading to local differentiation in dental morphology among biologically related groups over a relatively short period are generally viewed as a consequence of colonization events, population structure such as high rates of endogamy, and small population size (Scott and Turner, 1988).

\section{CONCLUSIONS}

This study revealed that the living Jordanian Arabs have a unique dental morphological pattern that sets this group apart from the Western Eurasian and other world groups. This pattern, in contrast to that of the Western Eurasian, is characterized by more trait elaboration than trait rarity or absence. Statistically significant sexual dimorphism has been found in the occurrence of three crown traits in the direction of stronger trend toward crown morphological simplification in females involving accessory tubercles as well as minor and major cusps in the molar region. The relatively large biological distance values of the living Jordanians from the Western Eurasian groups, with whom they share a recent common ancestor, suggest that this population has undergone a major genetic drift leading to a distinct dental morphological pattern for this population from the Caucasoid dental pattern over a relatively short time span.

\section{LITERATURE CITED}

Aas IHM, Risnes S. 1979a. The depth of the lingual fossa in permanent incisors of Norwegians. I. Method of measurement, statistical distribution and sex dimorphism. Am J Phys Anthropol 50:335-340.

Brewer-Carias CA, Le Blanc S, Neel JV. 1976. Genetic structure of a tribal population, the Yanomama 
Indians. XII. Dental microdifferentiation. Am J Phys Anthropol 44:5-14.

Constandse-Westermann TS. 1972. Coefficients of biological distance. Oosterhout N. B. The Netherlands: Anthropological Publications.

Corruccini RS, Sharma K, Potter RH. 1986. Comparative genetic variance and heritability of dental occlusal variables in US and northwest Indian twins. Am J Phys Anthropol 70:293-299.

Dahlberg AA. 1965b. Geographic distribution and origin of dentitions. Int Dent J 15:348-355.

Dahlberg AA. 1986. Ontogeny and dental genetics in forensic problems. Forensic Sci Int 30:163-176.

Garn SM, Lewis AB, Kerewsky RS. 1966d. Extent of sex influence on Carabelli's polymorphism. J Dent Res 45:1823.

Goose DH, Lee GTR. 1971. The mode of inheritance of Carabelli's trait. Hum Biol 43:64-69.

Harris EF. 1977. Anthropologic and genetic aspects of the dental morphology of Solomon Islanders, Melanesia. PhD dissertation, Department of Anthropology, Arizona State University, Tempe.

Harris EF. 1980. Sex differences in lingual marginal ridging on the human maxillary central incisor. Am J Phys Anthropol 52:541-548.

Harris EF, Sjøvold T. 2004. Calculation of Smith's Mean Measure of Divergence for intergroup comparisons using nonmetric data. Dental Anthropology 17:8393.

Irish JD.1993. Biological affinities of late Pleistocene through modern African aboriginal populations: the dental evidence [dissertation]. Arizona: Arizona State University.

Kaul V, Prakash S. 1981. Morphological features of Jat dentition. Am J Phys Anthropol 54: 123-127.

Kieser JA, Preston CB. 1981. The dentition of the Lengua Indians of Paraguay. Am J Phys Anthropol 55:485490.

Kirveskari P, Alvesalo L. 1982. Dental morphology in Turner's syndrome (45,X females). In: Kurtén B, editor. Teeth: form, function, and evolution. New York: Columbia University Press. p 298-303

Mayhall JT, Saunders SR, Belier PL. 1982. The dental morphology of North American whites: a reappraisal. In: Kurtén B, editor. Teeth: form, function, and evolution. New York: Columbia University Press. $p$ 245-258

Miller RG. 1966. Simultaneous statistical inference. New York: McGraw-Hill.

Mizoguchi Y. 1985. Shovelling: A statistical analysis of its morphology. Tokyo: University of Tokyo Press.

Nichol CR, Turner CG II. 1986. Intra- and Interobserver concordance in classifying dental morphology. Am J Phys Anthropol 69:299-315.
Rao CR. 1952. Advanced statistical methods in biometric research. New York: Wiley.

Rothhammer F, Lasserre E, Blanco R, Covarrubias E, Dixon M. 1968. Microevolution in Chilean populations. IV. Shovel shape, mesial-palatal version and other dental traits in Pewenche Indians. Z Morph Anthropol 60:162-169.

Scott GR.1973. Dental morphology: A genetic study of American White families and variation in living Southwest Indians. Unpublished dissertation. Arizona: Arizona State University.

Scott GR. 1977a. Classification, sex dimorphism, association, and population variation of the canine distal accessory ridge. Hum Biol 49:453-469.

Scott GR. 1980. Population variation of Carabelli's trait. Hum Biol 52:63-78.

Scott GR, Dahlberg AA. 1982. Microdifferentiation in tooth morphology among Indians of the American southwest. In: Kurten P, editor. Teeth: Form, Function and Evolution. New York: Columbia University Press. p 259-291.

Scott GR, Turner CG II. 1988. Dental anthropology. Ann Rev Anthropol 17:99-126.

Scott GR, Turner CG II. 1997. The anthropology of modern human teeth: Dental morphology and its variation in recent human populations. Cambridge: Cambridge University Press.

Scott GR, Potter RHY, Noss JF, Dahlberg AA, Dahlberg T. 1983. The dental morphology of Pima Indians. Am J Phys Anthropol 61:13-31.

Sofaer JA, Smith P, Kaye E. 1986. Affinities between contemporary and skeletal Jewish and non-Jewish groups based on tooth morphology. Am J Phys Anthropol 70:265-275.

Townsend GC, Brown T. 1981. The Carabelli trait in Australian aboriginal dentition, Arch Oral Biol 26:809-814.

Townsend GC, Richards LC, Brown T, Burgess VB, Travan GR, Rogers JR. 1992. Genetic studies of dental morphology in South Australian twins. In: Smith P, Tchernov E, editors. Structure, function and evolution of teeth. London: Freund Publishing House Ltd. p 501-518.

Turner CG II. 1969. Microevolutionary interpretations from the dentition. Am J Phys Anthropol 30:421-426.

Turner CG II. 1987a. Late Pleistocene and Holocene population history of East Asia based on dental variation. Am J Phys Anthropol 73:305-321.

Turner CG II, Nichol CR, Scott GR. 1991. Scoring procedures for key morphological traits of the permanent dentition: the Arizona State University dental anthropology system. In: Kelley MA, Larson CS, editors. Advances in dental anthropology. New York: Wiley-Liss. p 13-31. 